\title{
FAULT DETECTION AND DIAGNOSIS OF POWER CONVERTERS USING ARTIFICIAL NEURAL NETWORKS
}

\author{
K.S.Swarup \\ H.S. Chandrasekharalah \\ Department of High Voltage Engineering \\ Indian Institute of sclence \\ Bangalore 560012 . INDIA.
}

\begin{abstract}
Aberact: Pault detection and diagnosis in real-tine are reas of research inferest in knowledge-based expert aytema. Rule-based and model-based approaches have been - uccessruliy applied to some dowains, but are too sior to be effectively applied in a real-tiae environment. This paper explores the suitability of using artificial neural netvorks for fault detection and diagnosis of power converter syatems. The paper describes a neural network design and simulation environment for real-time reult diagnosis of thyristor converters used in HVDC power transeission syeteras.

Ley words: Pault detection and diagnosis, neural network, converter.
\end{abstract}

1 INTRODUCTION

An important application of artificial Intelligence (AI) 18 the dagnosis of faults of mechanisms and systems in general. Traditional approaches to the problex of diagnosis is to construct a heuristic, rule-based system unich embodies a portion of the complied experience of a human expert. These systems perfora dlagnosis by mapping fault symptoms to generated hypothesis to arrive at diagnostic conclusions. Second generation expert agstem, also termed as nodel-based ressoning perform diagnosis based on the structure and behaviour of the physical systea. Model-based expert oystems apply a qualitative sodel of numerical - Imulation of the problem donain in the diagnoatic procesa. Thege aysteas reason on the basis of physical principles and therefore are capable of performing diagrosis for a wide range of inputs. Application of rault-based and model-based qualitative reasoning for power syster rault diagnosis discused by the authors in [9] provides an comparative and integrated approach or integrated diagnostic systea for efficient problea solving. The search process involved, in second generation systens 18 exhaustive and hence time consuaing. Also sivulation of models are usually too Liou to be effectively applied in a real-time environment. Knowledge acquisition is a problem shared by both rule and oodel-based expert systens. Rule-based yaremo mut of ten be tediously hand encoded and are not autable for representing non-causal knowledge.

Artirlctal neural networks (ANN) are found to be untable for the above requirements. Artifictal neural netvorka are asoively parallel interconnected netrorks of ciple adaptive elementa and their hierarchical organizations wich are intended to interact with the objects of toe real vorld in the same way as the Mological counterparta[1, 2, 3]. Neural networke find wde application in perallel diatributed procesalng and in real-tice environienta. Weural network have conaiderable advantages over expert gystems in terms of knowledge acquisition, addition of new knowledge. performance and speed[4]. Recently intereat in the application of associative mewories and neural networke to problems encountered in diagnostic expert systems developaent has increased. Neural networks appear to offer features which colncide well with the requirements of pattern-based diagnosis. An 1mportant feature of rault diagnosis using neural networks is that they can interpolate among the training to give an appropriate response for cases described by nelghooring or notey input data. This paper gives in brief the, design and -1mulation of an neural netrork for real-tiee reult diagnosis of thyriatore converters used in HVDC pover transasaton systema. In thlo paper fault diagnosis is conceptualized as the asociation of patterns of input data representing the behariour of the physical systes to one or more fault conditions. The fault diagnostic systen consisting of a two-level neural network wa trained using data fros the digital simulation of a twoterminal dc systea. The network model detects the severity and duration of the rault: The top-level netrork 18 trained with 14 input representations, 18 asociated with converter raults and elght with externil raults. The four lower level networks are asocinted with each clasaffier are designed to categorize input patterna according to fault everity and duration. Mine input patterns, consisting of combinations of three level geverity levels and tbree durations are used to train the lower level networks. Twenty four different raults were considered and the network was able to detect, classify and diagnose the type, duration and severity of the fault. The performance of the neural networik for fault detection and diagnusis under tre presence of external nolse and ras found to be eatieractory.

2 NEURAL NETWORKS POR PAULT DETECTION ARD DIAGNOSIS

Neural networks is one of the fantest growing areas of artificial intelitgence. Neural networks as inherently parallel achines and as a rebult, they can oolve problems much faster that a serial digltal computer. In addition, many neural networks have the ability to learn nonifnear relationships. Instead of prograwing these nets, they are presented with a serses of examples frow which the governing relationstips ape learned. Neural networke are masstvely paraliel interconnections of simple adaptive elements. Figure 1 show the topology of the neural network exployed in the current research. The basic unit of a neural network 10 a processing element or a node. Each processing elegent wbially has one or more inpute and a single output. These processing eletents are wost elegantiy described by a saple function providing a rapping from ndimenstonal space (tnpute) to one dimensional space (outpue).

Real-tifne diagnosiz of raults occurring in cooplex ystese $1 \mathrm{a}$ an acive area of research in the field of knowledge-based expert byatems. Real-time envfronments present many challenges onch aust be effectively and 
Ciclently addressed by expert oystem desinner. A realtise diagnostic Bystem must be capabje of purforning an accurnte diagnosis quickly enough for effective remedial action to be taken. Recently there has been growing interest in the application of associative inemories and neural networks to probleme encountered in expert eycteiss. Most of the earlier vorks deal with the application of asolctalve memorles and neural networks to pattern recognition and mapping $[4,5]$.

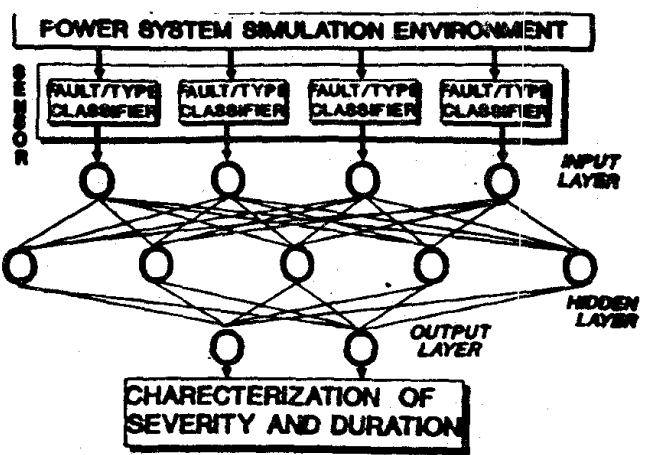

P1gure 1 Meural network topologs.

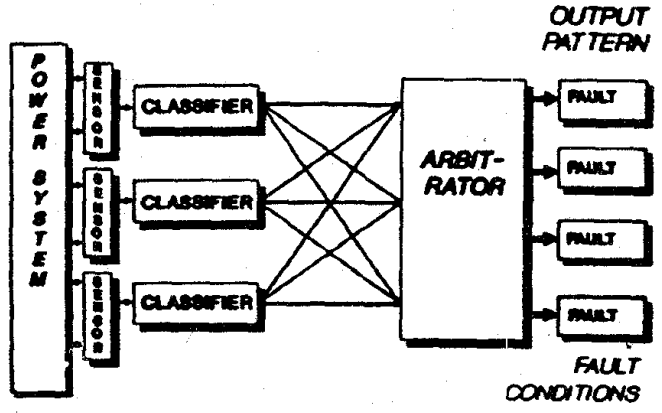

P1gure 2. Pattern-based diagnosie.

The behaviour of physical syotes 18 orten described in terms of the temporal behaviour of various phyalcal parameters relating to the systes. Pigure 2 chows the basic principle of the diagnostic process conceptualized as mapping of patterng of Bensor data to a pattern associated with a fault condition. Each senmor 1. associated with a classirying oystem, wich deterines the fault condition indicated by the sensor. $A$ real number between 0 and 1 is output by each cleal number between porsible fault condition. The output classifler for each possible fault condition. The output of each classirier then 18 input to an aroitrator which determines the output of the diagnostic syotes. The aroitrator combines the outputs of the claselfter and outputs a pattern of real numbers correaponding to the output of the system as a whole. The arbitrator aay axply average the outputs of the senoors, or it as apply appropriate domain knowledge from the exper oystem and sobign some sensors more velgkt than others. The calculation of the output of the neural networ involves only two matrix sultiplications and two applications of the activation functions. the uec of neural networks require very little computational overnead and allow diagnosis to be accouplished in real-time[5]. The algorithw for training the neural netrorks is written in FORTKAN as the neural networks involve mostly mathematical calculationa, rather than -ymbolic manipulations.
3 LEARNING.

Artificlal neural networke learn patterns of activations and hence, learning can be equated to determining the proper values of the connection strengths that allow all the nodas to achieve the correct tate of activation for given pattern of 1nputs. Once the pattern of activation is eatablished. the resulting outputs let the network clasisy an input pattern. The adaptive nature of the neural network allow the welghto to be learned by experience, thus producing a self-organizing eystes. Much of the recent interest in neural networke can be attributed to new and -ore effective learning heuristics. A robust learning heuristic for mult-1ayered feed forward neural network called the Generallzed delta rule (GDR) or back propagation learning rule has been recently proposed by Rumaeinart [4, 12, 13]. The back propagation training a goritho 16 an Iterative gradient algoritho dealgned to untmize the mean square error between the actual output of a three layer feed rorvard neural network and the desired output. It uses a gradient search technique to minialze a cost function equal to the mean oquare difference between the desired and the actual net outputa. The desired output of all the nodes $1 \mathrm{~s}$ lor (0.1) unlese the node corresponding to the class the current input is frou in vhich ease it 1. high $(0.9)$. The neural network is trained by initially selecting - 11 rando weighta and internal thresholds and then presenting all training data repeatediy. Welghto are a jueted arter every trail ualng inforeation opecifying the appropriate desired fault condition. The back propagation algorith propagates error teres to adapt veights from nodes in the output layer to nodes in the bidden and input layer. This algorith has been modifled to the requirements of fault analyois in pover converters and applied in the research effort.

\subsection{Back Propagation Algor1thn:}

Let $M, N$ and $P$ be the number of nodes in the input hidden and output layer reapectively. Let $X(I), Y(J)$, $Z(K), I=1, N ; J=1, N ; K=1, P$, be the pattern rectora at the 1nput, hidden and output layere respectively. $B(J)$, and $D(K)$ are blas of orfaet vectors in the bidden and output layers respectively. $v(I, J)$ and $W(J, K)$ are the connection weighte in the input to hidden layer and hidden to output layer.

The computation of output of the input layer 1 g given by (Input to hidden layer)

$$
\begin{aligned}
& \gamma=1 /(1+\exp (-(Y)) \\
& 2 J
\end{aligned}
$$

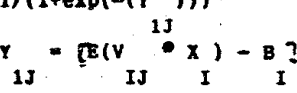

Conputed output:

$Y=1 /(1+\exp (-(Y)))$

Aapting weights

Error tere in output layer

$D_{1 X}=Y \cdot(1-Y) \cdot\left(Y-D_{X}\right)$

Error tere In hidden layer:

$D_{2 J}=Y_{2 J}-\left(1-Y_{2 J}\right) \cdot\left[E\left(w_{J K} \bullet D_{1 K}\right)\right\}$

Adapting velght without momentus function:

$v=v+u * 0 * \frac{1}{2}$

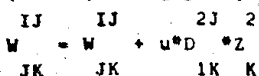

Adapting velghts with momentum function:

$v(t+1)=v(t)+u=D=x+a \cdot c v(t)-v(t-1)$. $W_{J K}^{J J}(t+1)=W_{J K}^{I J}(t)+U=D_{1 K}^{2 J}=Z^{2 J}+a \cdot\left[J_{J K}(t)-W_{j K}(t-1)\right.$ 
4 AN INTRODUCTION TO THE PROBLEM OP PAULT

DIAGNOSIS OP PONER CONVERTERS

Thyrlotor power converters are widely used in high voltage direct current (HVDC) power trangmise1on -yotems. Power converters usually constitute a $\mathrm{glx}$ pulse Graetz bridge circult or a twelve pulse converter. Power transasalion enrough direct current constitutes an important and integrated part of AC system. Pault detection and diagnosis of HVDC systems is an essential aspect of study for the rellable operation of the integrated power system. The task of detection and diagnosis of faulte on converters are usually perforwed with the help of icroprocessors which monitor continuousiy the performance of the converter under different operating conditions. A new approach to : fault derection and diagnosis of nudc systems has been proposed by the authors where the conduction patterns of the thyristors of the converter are used for the development of Pault Diagnostic Expert system (PDES) for rault detection and diagnosis of HVDC aystems $[6,7$, 8). The patterns of voltage-zone perlods and pulse-zone periods are also used for diagnosing the fault. A typlcal bridge conduction pattern consisting of patterns of conducting thyristors, voltage-zone periods and pulee-gone periods la given in figure 3 .

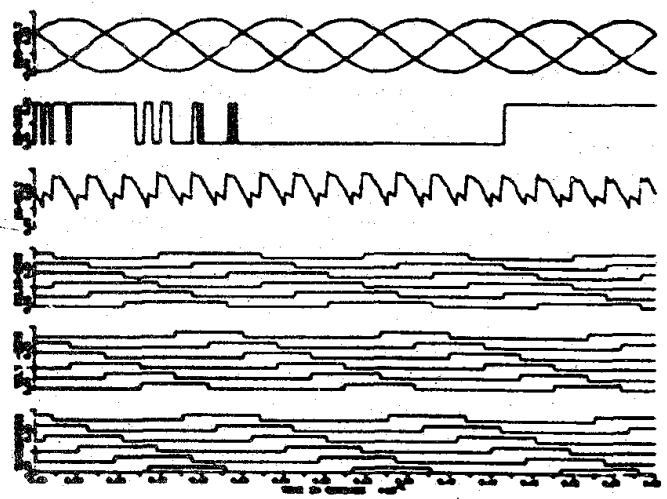

Plgure 3. Typlcal bridge conduction pattem of converter.

5 MEURAL METHORE DESIGN

A two layer neural network consiating of 24 input nodes, 10 hidden nodes and 6 output nodes are used. Out of the 24 input nodes, six nodes each are ailocated for the thyrigtor conduction pattern, voltage-zone periods and pulse-zone perlods, The remaining 6 nodes are allocated as follows; two for direct voltage and direct current, three for the ac system bus voltage and the last one for the tlae instant of sampling. The nodes in the hldden layer vere varied from 10 to 25 for every input pattern and the performance of the network in determining the optiwu hidden nodes was carried out. It was found that twelve nodeg in the hidden layer gave the mon opt imum and satisfactory performance in terms of ralt detection, diecrinination and diagnosta. The output layer consists of $81 x$ nodes corresponding to the difrerent fault condition on the convercer. six major rauts on the converter are considered. An input pattern correaponding to a particular faut condition is fed to the neural network and the desired output pattern corresponding to the fault condition is lmpressed at the output. The neural network is trained using the back propagation algorithe till the error in the wetghts between succesaive lterations 18 less than a specified ainimum value. The neural network is trained off-line for twelve different types of fauts and used on-line. Table 1 shows the training set for normal and abnormal operation of the converter. When an unknown output pattern corresponding to the fault condition is given at the output layer of the neural network, the diagnostic syetem clasifies the type duration and severity of the rault. The neural network 18 tralned with the help of tine data obtalned through the digital simulation of a two terminal dc-system. The neural network designed is able to determine the severity and duration of the rault. The structure of the prototype diagnostic system 18 given in rigure 4. Senaor data lo input to the neural network which has been trained to recognize the difference between the behaviour exhibited by converter raule and faults external to the converter. Once a grosg Identification of the fault has been wade, the sensor data 1 s passed to lower-level neural networks unich have been trained to recognize the severity and duration of the fault. Each classifier has tive assoclated neural networks, one to determine the type of the raul and four to determine the severity and duration of converter and external faulta. The top level neural netvorks have two output nodes. One output node 1s activated if a converter fault is detected, while the other 18 activated if external faulto are detected. The output activations are real numbers between 0 and 1 . Thto output format allows a network to indicate that an input behavioral pattern exhibits features comon to both fault scenarlos. Lower level networks have fous output nodes, each of which identifles either one of the four severity levels or one of four durations. Data frob the four sensors are fnput into the four top level neural networks, each of which independently attempts to identify the fault condition. If a network recognizes an input pattern as characteristic of a converter fault, the node associated with converter faults will be highly activated. Corresponding output activations from each top level network are averaged to yleld the overall toplevel response to the input. patterns. The result is a cbaracterization of the fault as elther converter fault or external fault. The diagnostic system now attempta to determine the severity and duration of the rault. This is accomplished by applying the sase -imulation data which was used for the top-level fault identification to the lover level neural networks. Eacb censor vill input information into two neural netrorka, one which determines the fault severity and one which deterines the duration.

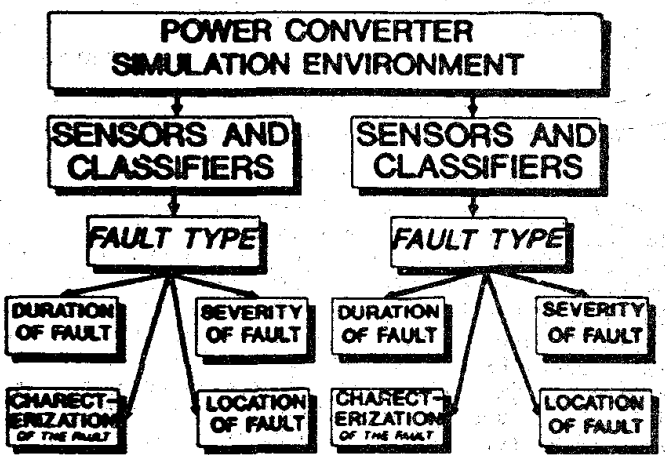

Pigure 4. structure of a prototype diagnostic ajoten.

5.1 Behurioral representation

To train and use neural networks, behavioral data must be presented to the inputs of the networks. Two methods of representing behavioral data have been considered in this paper. In the first ethod, - 1mulation data 1s presented to the input layer of the neural network as a vector of continuous real varlables. Each node in the input layer corresponds to a potnt in time oince a fault was detected. The activation of each input node is the magnltude of a parameter at each polnt of time. Therefore, each input node represents a sample of the data at different imes. In the procotype 
Dientitation, 20 input nodes were used, oparining a 2.0 second interval. As a regult the adjacent linput nodes contain data 0.1 seconds apart. Ten nodes were ut1l1zed in the hidden layer. In the second method, parameter behaviour is represented in a binary form. The wavefor describing the temporal behaviour of the converter 1a represented as a field of $O^{\prime}$ a and I's corresponding to the off and on tates of the thyristors of the converter. The rield lo represented as a olngle olnary vector which la preaented to the input of tihe neural network. Twenty tide intervalo and twenty magnitude intervals are encoded. As a result, the neural network for this representation requires 400 input nodes. Plve hidden nodes were utilized in this implementation.

\subsection{Training the neural network}

The fault diagnostic system was trained using data from the digital simulation of a two terminal de eystea. The training process used for a top-level inetwork is shown. The network has two output nodes, each of which 1. associated vith elther a converter fault or an external fault. During training, a behavioral pattern representing a faul condition 18 applied to the input level, while a 1, indicating the full activation io applied to the corresponding output node. The generallzed back-propagation algorithm 18 then invoked to adjust the connection weights to be consistent with the imposed input and output patterns. At this point the network has been trained to recognize a single representation of a converter fault. The training process is now repeated with a representation of the external (dc-line) fault presented to the input nodes, and an activation of 1 imposed on the corresponding output node. The connection veights are readjusted to accomodate the new input. During the process, the ability of the network to recognize the first input will be degraded. The network aust in effect be repeatedly retrained on the two scenarios until the gystes or relghts converges to eteady otate value.

Table 1. Training oet for learning in network

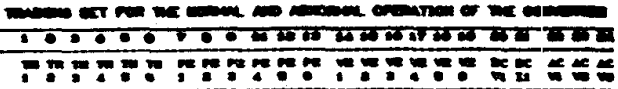
tomenconom

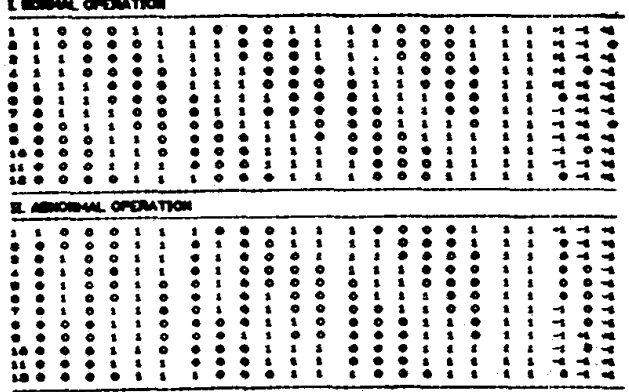

A training set of gore than one input pattern 18 to be associated vith a particular output. Por instance o1x different converter faulta are associated with the output assigned to identify them. Similarly eight external fault patterns are associated with the output node signifying the identification of an external fault. A a result, each top-level network is trained with in input representatione. Ix sesociated with converter

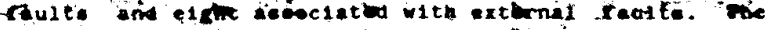
cour lover-ietel network abockated with bech classifier are designed to catesorize infut pettern. zecording to fault ceverity and duration. Mine input patterns. consisting of conbinations of three severity levelo and three durations, are used to trann the lover. level netrorke. Each lover-level thite outpute,
correponding to the different levelo of severty os duration, depending on how the network is tralned. The eeverity claseffiers are taught. that all faults of the same severity are to be classifled together, regardless or the fault duration. The networks deaigned to clasatfy rault durations are taught that all faulta of the sase duration are to be clasolfled together regardless of the severity of the fault. The ane input patterns are used to train each network ( now the training patterne are grouped determines the (unction of the network). Training represents the most computationally intensive aspect of the development of a neural network-based diagnostic gyaten. The time required to training. network can vary widely, depending on the number of nodes in a network and the number of training sets uged. However, the simllarity of input representations in the training bet has the wost elgnificant effect on training times. If two input representations are nearly equivalent, but are required to activate difrerent output nodes, the training tines can be excessive. In the rault diagnoatic asten deccribed in this paper, the neural netrork 18 trained for 800 to 1000 presentatione of input and output patterns. The top-level network wach contalned a large number of simlar patterns which vere required to activate different autput nodes, required over 2000 presentatione of data for convergence of the reights to be achleved.

\subsection{Results of Power converter diagnosis}

Th1s paper (testing and evaluation of the power converter diagnost1c syotem) has rocused on the ab111ty of the gyatem to correctly diagnose fault conditions of varying degrees of severity and duration. Input patterna representing either a converter cault or external rault patterns were presented to the inputs of the top-level netrorks. The oystem was evaluated on the basis of 1) whether the top-level networks correctly identifled the rault condition, and 2) whether the lower-level networks correctiy identifled the severity and duration of the fault. Severity and duration conbinations were chosen wich were not in the training aets of the neural networks. All real-tiae environeent exh1bit bose level of noise rros inetrupentation. The efrects of noise on the response of the diagnostic systen vere assessed by randoly perturolng the inputs to the neural networks. The diagnostic aysteme utilizing either the first or second rethods of input data representation (continuousvariable or binary input, respectively) successfully differentiated between a converter fault and an external fault. The different input patterns and output fault conditions derived theoretically for normal and abnoral fault conditions used to train the neural network 18 $g 1$ ven in table 1. An taportant advantage of the neural network based diagnosis is its perforance in real-tine enviroments and under the influence of nolsy or varied input data, thus exhibiting resilience.

\section{Conclusions.}

Application of artificial neural networks for fault detection and diagnosis of thyriotor power converter used in HVDC power tranemisiton is described in this paper. Sultability of the neural network for patternbased diagnosis is justified vith the help of a case ctudy. Neural network are moet sultable for diagnosis under real-tine environments. Also neural networks are sulable in altuations where acquisition and representation of knowledge are the bottlenecks in developing expert gystems. To achieve better performance of the alagnostic bystem, two Aeural networks one for detectioc the faujt ood the gther for dragnoeing the

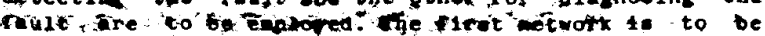
traines for alcrerute the lnatent of the enyrietors conduction patterne, hence detecting the inatant of occurrence of the fault corresponding to the abnoral behavtour of the converter. The eecond network is to be tralpes for different duratione of che patterns of conductits thifrictore, voltage zone periods end pulse zone perlods. The two netmonk are to interact with the 
sed expert oystem and provide a efricient ach to real time fault detection and diagnosis.

.EPERENCES

1. Hopfleld J, J Neural networks and physical systeas with emergent collective computational abilities", proceedings of the National Academics of Science, USA, Blophye1CB, 79, April 1982, pp 2554-2558.

2. Hopfield J, J and Tank D, Neural computation of decieion: in optinization problems", Blological cybernet1ca, 52, Springer Verlag, 1985, pp141-152.

3.Hopl1eld J, J, and Tank D, W. "Computing with neural networks: A mode1". Science 233, August 1986, pp625-633. 4. Lippmann. $R$ " An introduction to computing with neural network". IEEE ASSP Magazine, August 1987, pp422.

5. Sobajtc $D$ and $P a o Y, H$ Artificial neural network based dynamic security asessment for electric pover aytems". Case Western Reserve University,

6.Swarup, K. S and Chandrasekharaiah H, S "PDES: Pault Diagnosis expert systens for HVDC sybtems", Second -ysposium on expert system application to power systeas, University of Washington, Seattle, August 1989, pp 296302 .

7. Swarup $K, S$ and Chandrasekharaiah $K, S$ " Expert systes approach to rault dagnosis of HVDC eystese", Journal of the Indian Institute of science, Spectal 1 arue on $A I$ and expert systems at I.I.SC, May-June 1990, $70(3), p p 249-268$.

8. Swarup, K S and chandrasekharaiah H, C Pattern directed inference system for fault classification and nalysis", Sixth National Power Syatems Conference, Bombay, June 1990., pp 145-150.

9. Swarup, $K$. S and Chandrasekharalah $H, S$ "Integrating complled and deep level reasoning for power system fault diagnos10", paper cubmitted to PICA 90 conference

10. Ebron S A neural network processing strategy for the detection of high impedance faults", Master's thests, Electrical and Computer engineering department, North Carolina State University, NCSU, 1988. Technical report, TR87-135, Decenber 1987.

11. Wasserman $P$, $D$ Neural computing-Theory and practice*, van Reinhold, NY 1989.

12. Rumelhart $D$, and Mc Celland $J$, "Parallel dietributed processing: Explorations of the -1crostructure of cognition", Volumes $I$ and II, MIT Pres8, Cambridge, Mass. 1987.

13. Rosenblat $R$, "Principles of Neuro dynasics", New York, Spartan, 1962. 